\title{
Preventing Paediatric Scalds: A 5 Year Descriptive Analysis, Do We Need to Change Our Approach?
}

\author{
Noman Saghir ${ }^{1, *}$, Joseph Stallard ${ }^{1}$, Reyan Saghir ${ }^{2}$, Alan Phipps ${ }^{3}$, Umair Anwar ${ }^{3}$, and Preetha Muthayya ${ }^{3}$ \\ ${ }^{1}$ Plastic surgery specialty Registrar, University Hopsital, North Durham, Durham, DH1 5TW, United Kingdom \\ ${ }^{2}$ Foundation Doctor, Huddersfield and Calderdale foundation Trust, United Kingdom \\ ${ }^{3}$ Burns \& Plastic Surgery Consultant, Pinderfields General Hospital, Regional Burns Centre, Wakefield, United Kingdom
}

*Corresponding author: Noman Saghir, Plastic surgery specialty Registrar, University Hopsital, North Durham, Durham, DH1 5TW, United Kingdom, E-mail: drnomansaghir@gmail.com

Received: 10 Jul, 2021 | Accepted: 17 Jul, 2021 | Published: 20 Sep, 2021

Citation: Saghir N, Stallard J, Saghir R, Phipps A, Anwa U, et al. (2021) Preventing Paediatric Scalds: A 5 Year Descriptive Analysis, do we Need to Change our Approach? J Surg Open Access 7(4): dx.doi.org/10.16966/2470-0991.249

Copyright: (C) 2021 Saghir N, et al. This is an open-access article distributed under the terms of the Creative Commons Attribution License, which permits unrestricted use, distribution, and reproduction in any medium, provided the original author and source are credited.

\section{Abstract}

Introduction: Scald injuries are the most common type of thermal injury in the paediatric population [1]. Despite domestic accidental scalds being so common, there is limited awareness of the frequency and severity of these injuries. Awareness of trends in paediatric scalds including age, mechanism of injury and first aid would help guide future allocations of funding for burns prevention and first aid treatment in the paediatric cohort.

Methods: We searched the IBID database for all paediatric scald injuries that attended our burns unit between January 2014-19. Age demographic, incidence, mechanism, location of the scald, and first aid data was gathered, and descriptive analysis performed.

Results: Over the five year period, on average $50 \%$ of all paediatric burns in our unit were scalds. 0-2 year old age group presented with the greatest incidence of burns $(>50 \%)$ each year. $87 \%$ of all scalds took place in a private dwelling with $94 \%$ on caused by preparation or direct contact with scalding food/drink. Upto $10 \%$ of all scalds did not undergo any form of first aid.

Conclusion: As 0-2 year olds are dependants, we suggest targeting future scald prevention strategies at parents/carers of newborns during antenatal/ home visitor sessions as well as utilising the department of health personal child health record with a 'first aid' section including burns prevention, first aid and how to get help. Further research is scald prevention is essential to help prevent these potentially life changing injuries.

\section{Introduction}

Scald injuries are the most common type of thermal injury in the paediatric population [1]. Despite domestic accidental scalds being so common, there is limited awareness of the frequency and severity of these injuries. Public health campaigns have acknowledged this with 'Hot water burns like fire' campaign being the last media grabbing intervention to occur in the UK in April 2010. With the average cost of an uncomplicated minor scald $(<10 \%$ Total Body Surface Area (TBSA)) averaging $£ 1850$, preventing these injuries would avoid potentially life changing injuries, but also offer a significant relief of monetary burden on the NHS and should empower public health campaigns to target prevention strategies more appropriately [2]. Recent focuses on burns prevention have highlighted firework risks, whilst scalds continue to be the most common presentation to paediatric burns services [3].

We retrospectively reviewed five years data of all children (018 years) presenting to our burns service with scalds. We aimed to highlight the current trends in paediatric scalds identifying the commonest age group affected, mechanism of injury, and post-injury first aid therefore allowing focussed preventative strategies to be made.

\section{Material and Methods}

We searched our regional burns unit's International Burns Injury Database (IBID) over a 5 year period between January 2014-19 for all paediatric patients (0-18 years) that sustained a 'scald' as their mechanism of injury. Data regarding age, environment in which scald sustained, scalding agent and whether first aid was given, were collected and analysed in Microsoft excel. Descriptive analysis was presented graphically in the results below.

\section{Results}

\section{Age groups (Table 1, and figure 1)}

Patients were grouped in the following: $0<2$ years, $2<4$ years, $4<14$ years and $>14$ years old. The total number of patients per year ranged from the lowest in 2018 at 335 patients, the highest in 2016 at 434 patients. The mean number of scalds assessed per year was 308 . The majority of scalds occurred in the 0 to 2 year group (avg. $51 \%$ of total scalds). 


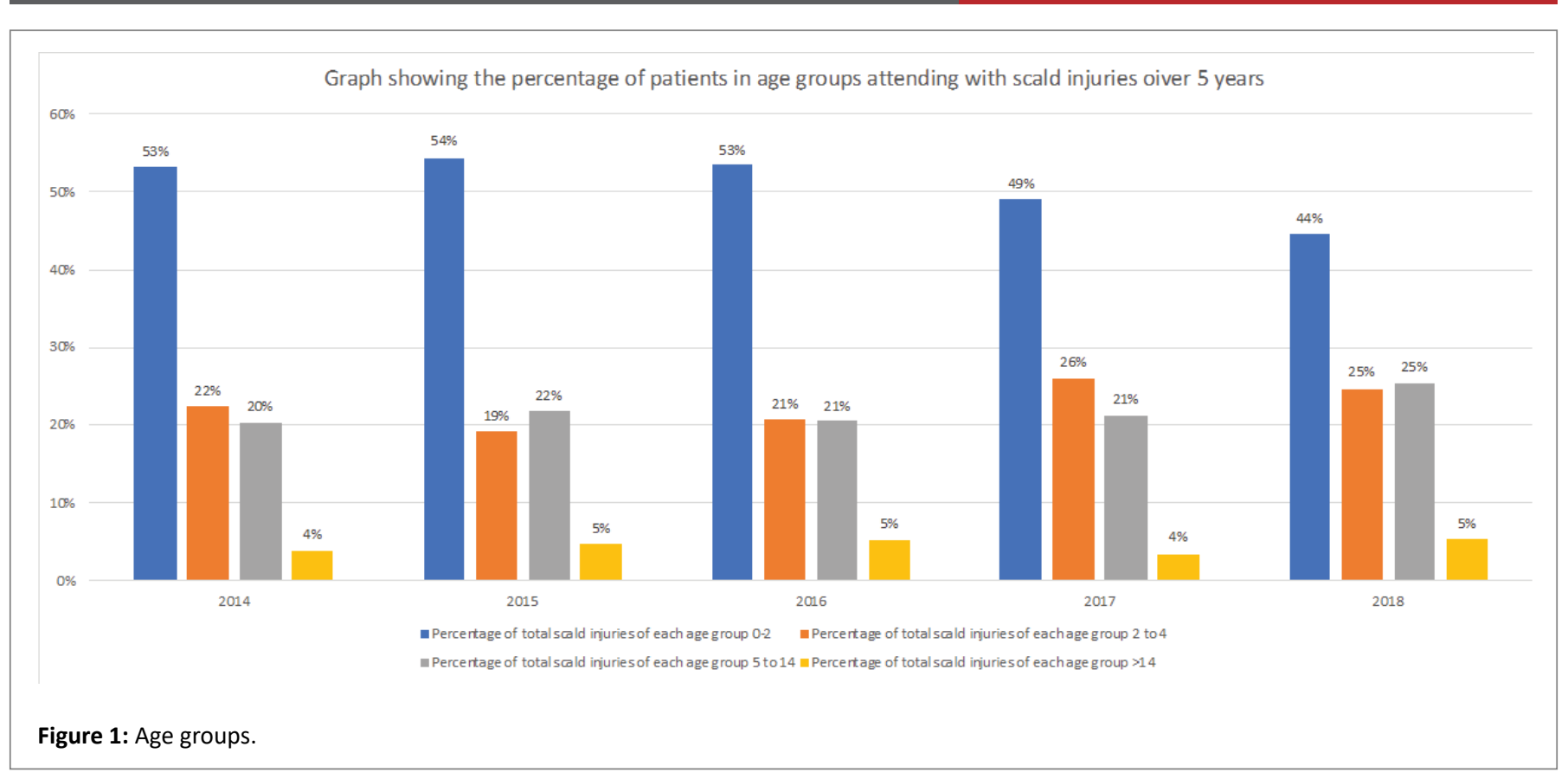

Table 1: Age groups.

\begin{tabular}{|l|c|c|c|}
\hline Year & $\begin{array}{c}\text { Total children's } \\
\text { burns assessed }\end{array}$ & Number of scalds & Incidence of scald \\
\hline $\mathbf{2 0 1 4}$ & 626 & 357 & $57 \%$ \\
\hline $\mathbf{2 0 1 5}$ & 766 & 381 & $50 \%$ \\
\hline $\mathbf{2 0 1 6}$ & 819 & 434 & $53 \%$ \\
\hline $\mathbf{2 0 1 7}$ & 796 & 395 & $50 \%$ \\
\hline $\mathbf{2 0 1 8}$ & 828 & 335 & $40 \%$ \\
\hline
\end{tabular}

Table 2: Table demonstrating total number of scalds in each age group by year.

\begin{tabular}{|l|c|c|c|c|c|}
\hline Year & $\mathbf{0 < 2}$ & $\mathbf{2 < 4}$ & $\mathbf{4 < 1 4}$ & $>\mathbf{1 4}$ & Total \\
\hline $\mathbf{2 0 1 4}$ & $190(53 \%)$ & $80(23 \%)$ & $73(20 \%)$ & $14(4 \%)$ & 357 \\
\hline $\mathbf{2 0 1 5}$ & $207(54 \%)$ & $73(19 \%)$ & $83(22 \%)$ & $18(5 \%)$ & 381 \\
\hline $\mathbf{2 0 1 6}$ & $232(53 \%)$ & $90(21 \%)$ & $89(21 \%)$ & $23(5 \%)$ & 434 \\
\hline $\mathbf{2 0 1 7}$ & $194(49 \%)$ & $103(26 \%)$ & $84(21 \%)$ & $14(4 \%)$ & 395 \\
\hline $\mathbf{2 0 1 8}$ & $149(44 \%)$ & $83(25 \%)$ & $85(25 \%)$ & $18(5 \%)$ & 335 \\
\hline
\end{tabular}

\section{Environment in which scald sustained (Table 2, and figure 2)}

Over the last 5 years the majority of scald injuries take place in the patients' own home (avg. 82\%). The remainder of the scalds occurred in another private dwelling (avg. 8.4\%) and a small percentage occurred in schools and other places (playgroups/outdoors).

\section{Agent causing scald (Figure 3)}

Tea or coffee have been shown to cause the majority of scald injuries in our regional burn unit between $45 \%$ (2014) increasing upto $61 \%$ (2018) of all scald admissions.
Environment in which the child sustained a scald injury (percentage of total)

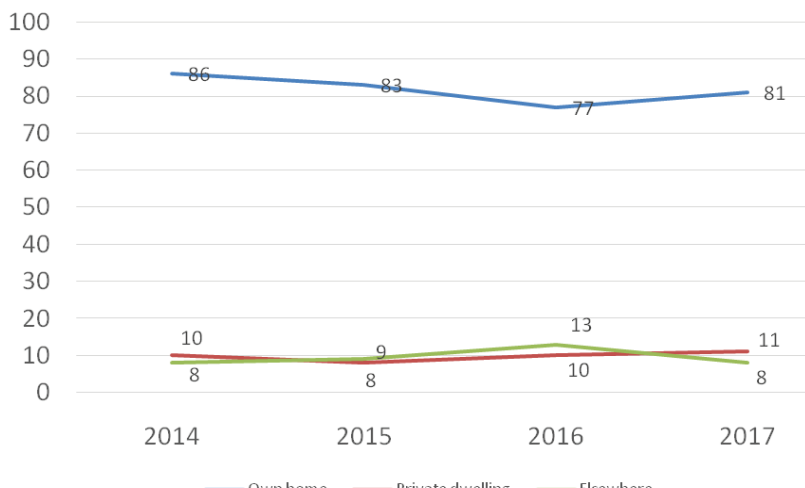

Figure 2: Environment in which scald sustained.

The average each year of cooking fluids, soup, milk, foods and bottles was $36 \%$, with hot water from kettle being (9.4\%). Bath water on average is the causative agent of scalds in $3.4 \%$ of cases each year.

\section{First aid (Figure 4)}

Any action to mitigate the severity of the burn was counted as first aid. On average over the 5 years, $88 \%$ of patients received some form of first aid following the injury, there was however a mean of 45 patients each year on are not receiving any form of first aid.

\section{Discussion}

Our burns service assessed a mean of 380 scalds each year and around half of those injuries were to patients aged under 2, with a fifth in each of the 2-4 and 5-14 year categories. Children under 2 years are developing hand-eye motor coordination and their primary aim is to pull items close to their face. They enjoy exploring relationships 
Percentage of each agent causing the scald injury each year

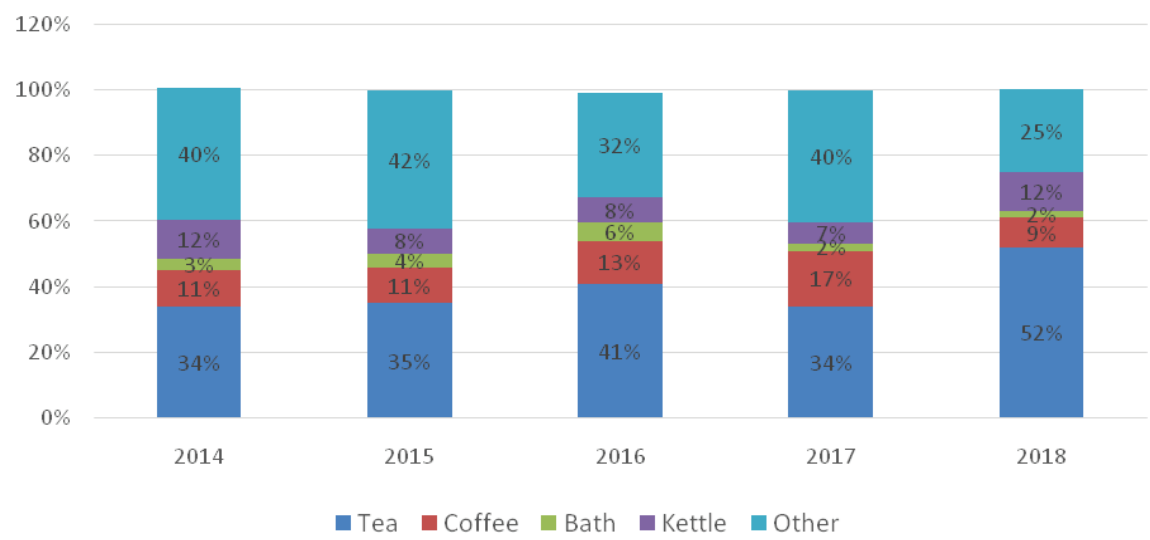

Figure 3: Agent causing scald.

\section{Percentage of patients that did not receive any forms of first} aid, per year

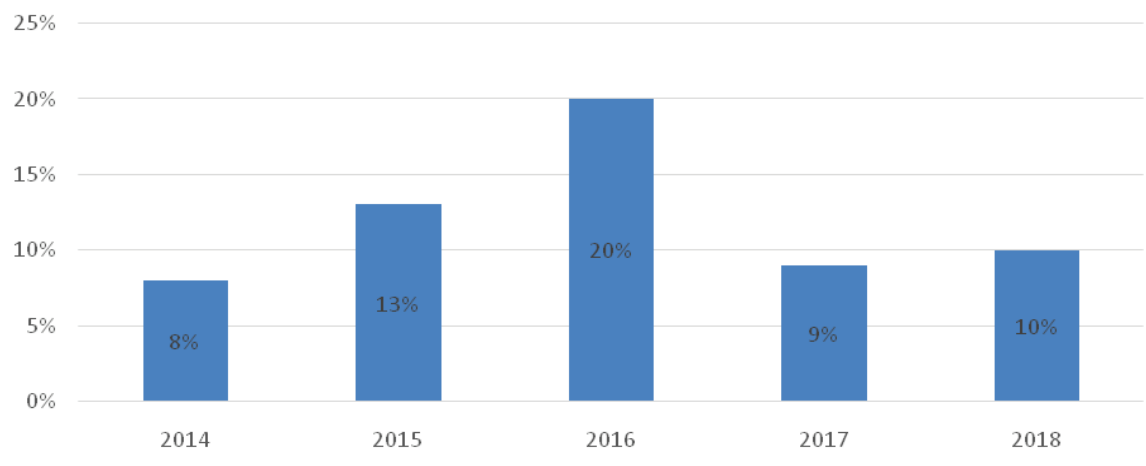

Figure 4: First aid.

between objects and surface properties, and may want to bang or pour things on the floor [4]. Access to hot beverages provides a ready means of sustaining scald injuries [5]. 0-2 year old children are entirely dependent on their parents/carers, with consistently highest scald incidence in this age group; we must target prevention efforts to the parents/carers of these children if we aim to reduce these numbers further.

"Hot water burns like fire" campaign ensured it was a legal requirement for all newly installed UK bath taps to have thermostatic mixing valves limited the temperature of its water to $48^{\circ} \mathrm{C}$ [6]. The percentage of bath scalds in our study had reduced; in 2017-18 only $2 \%$ of children had bath scalds. However, we acknowledge selection bias may be present as our unit as it does not manage large area burns (>10\% TBSA) which may be more associated in bath scalds. Spallek M, et al. in Australia assessed the use of scald prevention campaigns such as 'Hot water burns like fire' and identified that there was no significant reduction in scald injuries following the campaign [7].

After removal of bath scalds, the remaining mechanisms including preparation or direct contact to scalding foot/drink with beverages
(45-61\%), kettle (2-6\%), other scalding food/drink (25-40\%). All these mechanisms averaged $94 \%$ of all scald mechanisms each year. $88 \%$ occurred in either the patient's own home or another private dwelling. The health and safety executive in Ireland found $57 \%$ of scalds occurred in under 3 years old with 95\% of these occurring at home [8]. The UK are not alone, Lowell G, et al. identified $90 \%$ of the scald injuries in Chicago in under 5 year olds were related to hot drinks or cooking fluids/foods [3]. Burns awareness campaigns must therefore raise awareness of the potential dangers within the household environment with a particular focus on hot food and drink around young, especially wholly dependent children.

Bennett CV, et al. published a feasibility study assessing 'SafeTea'; a campaign that aimed to raise awareness of scald injuries and focussed on pre-school children in Cardiff. A multi-faceted approach, utilising printed material, activities and DVDs were used in an area of deprivation, followed up with pre-and post-intervention questionnaires along with focus groups. Although the results appeared encouraging, fewer than $50 \%$ of parents completed both pre and post- intervention questionnaires. They concluded the approach had merit but further evidence was necessary to ensure that the energy 
and funding required for such a community based intervention was useful [9].

An epidemiological study in Hong Kong reported upto 50\% of admitted burn patients did not have timely first aid and also demonstrated most commonly $0-2$ year age group to be affected [1]. Our data has shown that upto $10 \%$ of our scald patients had no first aid prior to assessment.

\section{Where should scald prevention be focussed based on our results?}

Targeting parent/carers of the potential hazards of hot food/ drink around 0-2 year old children is essential. We suggest accessing 'new' willing and engaging parents by utilising ante-natal classes and delivering information on preventing scald injuries with small group teaching/during a health visitor session should be trialled. The aim would be to highlight potential household dangers that can be avoided for these newborns.

Preventative information can be provided in the department of health, Personal Child Health Record (PCHR) 'red book' that follows a baby through its early year development. There is currently no 'first aid' section in this book, which would be very useful including a section on burns/scalds [10]. Scald prevention strategies should be directed towards children around hot food/drinks primarily ensuring they are out of reach as well as information of first aid and how to get help.

\section{Conclusion}

Under two year olds sustain over 50\% incidence of all paediatric scalds with $88 \%$ occurring in a household environment. $94 \%$ of all scalds are due to either preparation or directly related to hot food/ drink. 0-2 year olds are dependants and therefore we suggest accessing parents/carers in antenatal/healthcare visits as well as utilising PCHR (red book) to raise awareness of scalds as well as first aid management. Further research in this area is essential to help prevent these potentially life changing injuries.

\section{Limitations}

The limitations of this study are the reliance on the IBID database being upto date and having adequate information provided. We looked at 5 years of patient data in our regional burns unit. We believe the true incidence of scald injuries in our population may be much greater considering those managed in the urgent treatment centres and not referred to a burns service as well as those that don't seek medical help.

\section{References}

1. Tse T, Poon CHY, Tse KH, Tsui TK, Ayyappan T, et al. (2006) Paediatric burn prevention: An epidemiological approach. Burns 32: 229-234.

2. Griffiths HR, Thornton KL, Clements $C M$, Burge TS, Kay AR, et al. (2006) The cost of a hot drink scald. Burns 32: 372-374.

3. Lowell G, Quinlan K, Gottlieb LJ (2008) Preventing unintentional scald burns: Moving beyond tap water. Pediatrics 122: 799-804.

4. Adolph KE, Franchak JM (2017) The development of motor behavior. Wiley Interdiscip Rev Cogn Sci 8: 1-2.

5. Krishnamoorthy V, Ramaiah R, Bhananker SM (2012) Symposium on Pediatric Trauma Pediatric burn injuries. Int J Crit Illn Inj Sci 2: 128134.

6. Eadie PA, Williams R, Dickson WA (1995) Thirty-five years of paediatric scalds: are lessons being learned? Br J Plast Surg 48: 103105.

7. Spallek M, Nixon J, Bain C, Purdie DM, Spinks A, et al. (2007) Scald prevention campaigns: Do they work? J Burn Care Res 28: 328-333.

8. McGuire F, Hegarty M, Jennings P, Marsden P, Smith L (2017) Fancy a cup of scald? - The role of hot beverage burns in paediatric burns admissions in Ireland. Ir Med J 110: 583.

9. Bennett CV, Hollén L, Quinn-Scoggins HD, Emond A, Kemp AM (2020) Feasibility of Safe-Tea: A parent-targeted intervention to prevent hot drink scalds in preschool children. Inj Prev 26: 31-41.

10. DCHS (2020) DCHS-My personal child health record. 